\title{
Peritoneal Dialysis in Acute Kidney Injury: Trends in the Outcome across Time Periods
}

\author{
Daniela Ponce*, Marina Berbel Buffarah, Cassiana Goes, André Balbi \\ University São Paulo State- UNESP, Distrito de Rubiao Junior, Botucatu, Sao Paulo, Brazil \\ *dponce@fmb.unesp.br
}

\section{Abstract}

Peritoneal dialysis (PD) should be considered a suitable method of renal replacement therapy in acute kidney injury (AKI) patients. This study is the largest cohort providing patient characteristics, clinical practice, patterns and their relationship to outcomes in a developing country. Its objective was to describe the main determinants of patient and technique survival, including trends over time of PD treatment in AKI patients. This was a Brazilian prospective cohort study in which all adult AKI patients on PD were studied from January/2004 to January/2014. For comparison purposes, patients were divided into 2 groups according to the year of treatment: 2004-2008 and 2009-2014. Patient survival and technique failure

\section{Gopenaccess}

Citation: Ponce D, Buffarah MB, Goes C, Balbi A (2015) Peritoneal Dialysis in Acute Kidney Injury: Trends in the Outcome across Time Periods. PLoS ONE 10(5): e0126436. doi:10.1371/journal. pone. 0126436

Academic Editor: Antonio Carlos Seguro, University of São Paulo School of Medicine, BRAZIL

Received: February 5, 2015

Accepted: April 2, 2015

Published: May 12, 2015

Copyright: @ 2015 Ponce et al. This is an open access article distributed under the terms of the Creative Commons Attribution License, which permits unrestricted use, distribution, and reproduction in any medium, provided the original author and source are credited.

Data Availability Statement: All relevant data are within the paper.

Funding: The authors have no support or funding to report.

Competing Interests: Daniela Ponce is a PLOS ONE Editorial Board member. This does not alter the authors' adherence to PLOS ONE Editorial policies and criteria.

(TF) were analyzed using the competing risk model of Fine and Gray. A total of 301 patients were included, 51 were transferred to hemodialysis $(16.9 \%)$ during the study period. The main cause of TF was mechanical complication (47\%) followed by peritonitis (41.2\%). There was change in TF during the study period: compared to 2004-2008, patients treated at 2009-2014 had relative risk (RR) reduction of $0.86(95 \% \mathrm{Cl} 0.77-0.96)$ and three independent risk factors were identified: period of treatment at 2009 and 2014, sepsis and age> 65 years. There were 180 deaths $(59.8 \%)$ during the study. Death was the leading cause of dropout $(77.9 \%$ of all cases) mainly by sepsis $(58.3 \%)$, followed cardiovascular disease (36.1\%). The overall patient survival was $41 \%$ at 30 days. Patient survival improved along study periods: compared to 2004-2008, patients treated at 2009-2014 had a RR reduction of 0.87 ( $95 \% \mathrm{Cl} 0.79-0.98)$. The independent risk factors for mortality were sepsis, age $>70$ years, ATN-ISS $>0.65$ and positive fluid balance. As conclusion, we observed an improvement in patient survival and TF along the years even after correction for several confounders and using a competing risk approach.

\section{Background}

In the 1970s, acute peritoneal dialysis (PD) was widely accepted for acute kidney injury (AKI) treatment, but its practice declined in favor of hemodialysis [1-5]. Recently, interest in using PD to manage AKI patients has been increasing. It is frequently used in developing countries because of its lower cost and minimal infrastructural requirements [4-5]. However, in developing countries the infrastructure for quality research is often lacking and the result has been 
limited evidence on standardized treatment regimes such as indications, dosing and volumes, and technical failure and mortality. The studies performed by Po7nce-Gabriel et al. [6] showed that, with careful thought and planning, critically ill patients can be successfully treated by PD. To overcome some of the classic limitations of PD use in AKI, such as a high chance of infectious and mechanical complications and no metabolic control, they proposed the use of cycles, flexible catheter, and a high volume of dialysis fluid. It is also true that PD is not the most efficient therapy: clearance per exchange can decrease if a shorter dwell time is applied, a lower efficiency can be observed in large-sized and severely hypercatabolic patients, fluid removal can be limited, and there is a high risk of infection [7-11]. Given the paucity of good-quality evidence in this important area, additional large cohorts studies on the use of PD for AKI and its effect on clinical outcomes are necessary. The present study is the largest representative cohort study providing this information in the world. Large cohorts provide the opportunity to assess a wide variety of both exposures and outcomes. The information acquired from these studies is particularly important in fields where randomized clinical trials are difficult to perform. Another potential advantage of the analysis of large longitudinal cohort studies is related to the possibility of providing an overview of trends in patient and treatment characteristics. Therefore, the objective of the present study was to describe the characteristics of the population, clinical practice patterns, and their relationship to clinical outcome in a large prospective cohort. In addition, we aimed to analyze temporal trends in technique survival and outcome of AKI patients treated with PD.

\section{Materials and Methods}

\section{Study Population}

This study was a prospective cohort study approved by the ethics committee of the Botucatu School of Medicine, Sao Paulo, Brazil and the participants (or their legal caregiver) provided their written informed consent to participate in it. Three hundred and one patients who had been consecutively treated by high volume PD were evaluated between January of 2004 and January of 2014. The inclusion criteria were AKI patients according to Acute Kidney Injury Network criteria [12], and severe acute tubular necrosis (ATN) caused by ischemic, nephrotoxic injury or clinical diagnosis of septic AKI [13].

Indications for dialysis were uremia or azotemia (BUN $>100 \mathrm{mg} / \mathrm{dl}$ ), fluid overload (after diuretics use), electrolyte imbalance (K.6.5 mEq/L after clinical treatment), and acid-base disturbances (pH7.1 and bicarbonate $10 \mathrm{mEq} / \mathrm{L}$ after clinical treatment). Exclusion criteria were under 18 years of age, functional azotemia (by clinical definition, the integrity of renal parenchyma tissue was maintained and glomerular filtration rate was corrected rapidly, in less than $24 \mathrm{~h}$ on restoration of renal perfusion and glomerular ultrafiltration pressure, with normal urine sediment and fractional excretion of $\mathrm{Na}<1 \%$ ), urinary tract obstruction, acute interstitial nephritis, rapidly progressive glomerulonephritis (clinical criteria, defined as, absence of criteria for ATN, relevant clinical history and blood test with granular casts in urine sediment: red and white blood cells cast, proteinuria, or eosinophiluria $>5 \%$ ), a history of chronic kidney disease in advanced stages (IV and V), renal transplantation, pregnancy, severe hypercatabolism according to Schrier criteria [14], absolute contraindication for PD defined as recent abdominal surgery (less than one month), multiple abdominal surgeries (more than three), severe hyperkalemia with EKG changes, severe respiratory failure (FiO2> 70\%) and severe fluid overload (pulmonary edema) $[6,9,11]$. If patients presented any one of these contraindications, they were treated by intermittent conventional, prolonged, or continuous hemodialysis (HD) according to their hemodynamic instability. 


\section{Study Protocol}

One high volume DP session was defined as $24 \mathrm{~h}$ with sessions performed $7 \mathrm{~d} /$ wk. Peritoneal access was established by the blind percutaneous placement of a flexible catheter using a Trocathintroduced paramedian from 2004 to 2008 and Seldinger technique from 2009 to 2014. Cephazolin was used as a prophylactic antibiotic to cover the PD catheter insertion. Patients were treated with continuous high volume PD, and exchanges with Dianeal PD solution $(\mathrm{Na}=135 \mathrm{mEq} / \mathrm{L}$, $\mathrm{Ca}=3.5 \mathrm{mEq} / \mathrm{L}, \mathrm{K}=0 \mathrm{mEql} / \mathrm{L}, \mathrm{Mg}=1.5 \mathrm{mEq} / \mathrm{L}$, lactate $=40 \mathrm{mEq} / \mathrm{L}, 1.5 \%-4.25 \%$ glucose) were performed using HOMECHOICE cycler. The prescribed HVPD dose was determined by Kt/V [15], where $\mathrm{K}$ is the volume of dialysis solution prescribed in $24 \mathrm{~h}$ (in milliliters) $\mathrm{x} 0.6$ (considering the relationship of urea nitrogen (UN) dialysate/plasma $=0.6$ in 1 hour), $t$ is treatment duration ( 1 day), and $V$ is the volume (in liters) of body urea distribution by the formula by Watson et al [16]. The prescribed $\mathrm{Kt} / \mathrm{V}$ value ranged from 0.6 to $0.8 /$ session (mean was $0.67 \pm 0.11$ ) from 2004 to 2008 and 0.5 to 0.65 (mean was $0.57 \pm 0.06$ ) from 2009 until $2014 ; 1.5$ to 2 -L exchanges were performed with 30-60 minutes of dwell time (total of 32-44 L/d and 16-30 exchanges/d). To evaluate the adequacy of the dialysis, daily delivered Kt/V, ultrafiltration (UF), and patients' catabolic rates were calculated. The delivered high volume PD dose was determined by urea Kt/ $\mathrm{V}$, where $\mathrm{K}$ was the mean dialysate UN in milligrams per 100 milliliters/plasma UN pre- and post dialysis in milligrams per 100 milliliters X drained volume in $24 \mathrm{~h}$ in milliliters/volume of body urea distribution in milliliters [15,17]. Blood samples were collected at the beginning and end of each HVPD dialysis session and analyzed for creatinine, potassium, bicarbonate, glucose, and sodium levels. One aliquot of $3 \mathrm{ml}$ of all the spent dialysate was collected in every session to measure UN. Dialysate white blood cell count and cultures were also determined every 3 days.

Patients' catabolic rate was calculated based on nitrogen balance (NB), and patients were classified according to their NB as being mildly hypercatabolic ( $\mathrm{NB}<6 \mathrm{~g} / \mathrm{d}$ ), moderately hypercatabolic (NB between 6 and $12 \mathrm{~g} / \mathrm{d}$ ), and severely hypercatabolic patients (NB>12 g/d) [18]. Dietary protein was calculated from a 24 -h dietary intake of patients closely supervised by a renal dietician. Eight patients were excluded from the NB calculation, because they received an oral diet, leading to an unreliable measurement of protein intake. Anthropometric measurements (weight, height, and body surface area) were obtained before dialysis. Body surface area was calculated from the Du Bois formula [19]. Mobile patients were weighed on a digital scale, and the weight of immobilized patients was obtained by a bed scale or calculated from two variables formula [20]. Other variables, including the etiology of AKI, urine output, number of dialysis sessions, need for mechanical ventilation, presence of hemodynamic instability, and patient outcome, prognostic index of AKI evaluated by Acute Tubular Necrosis Individual Severity Score (ATN-ISS) [21], were analyzed. The ATN-ISS is a linear discriminant model producing a percent likelihood of mortality on the basis of a demographic data, causes of ATN, urine output, need for dialysis and clinical conditions.

The protocol was interrupted when there was partial recovery in renal function (urine output $>1000 \mathrm{ml} / \mathrm{d})$ and progressive drop in creatinine $(<4 \mathrm{mg} / \mathrm{dl})$ and BUN levels $(<50 \mathrm{mg} / \mathrm{dl})$, need to change dialysis method because of infectious and mechanical complications, or inefficacy of HVPD in failing to remove fluid and solute, treatment for more than 30 days of followup or death.

For the analysis of technique survival, the primary event was defined as transfer to hemodialysis (HD) for any reason, which means the patient did not return to PD until the end of the follow-up. Dropout data were stratified as death, recovery of renal function, and transfer to HD. For the description of trends in population characteristics, patient and technique survival, the population was divided into two groups according to the year of PD treatment: 2004 to 2008 and 2008 to 2014. 


\section{Statistical Analyses}

Results are presented as mean and standard deviation (SD) or median and range according to normality characteristics for each variable with a $5 \%$ significance level; $t$ test was used to compare parametric variables between two groups and ANOVA followed by the Newman-Keuls test for multiple comparisons between groups. For nonparametric variables, Wilcoxon and Kruskal-Wallis tests followed by Dunn's method were used to compare two groups and multiple groups, respectively. For analysis of repeated measures, the Proc mixed program was used.

Categorical variables were expressed as proportions and compared with the chi-squared test. Variables with p less than 0.20 in univariate associations were candidates for multivariable analysis.

We use a competing risk model based on Fine and Gray [22] for adjusted multivariate patient and technique survival. A competing risk is an alternative outcome that is of equal or more significant clinical importance than the primary outcome and alters the probability of the outcome of interest. That is, we limit our analysis to the consideration of two (competing) events: technique failure and deaths; deaths occurring after the TF are not considered in this analysis.

As opposed to a cause-specific analysis, which would censor the competing event(s), the Fine-Gray approach "carries forward" the competing event(s) in the risk set, with appropriate weighting, and does not censor them. The Fine-Gray model assumes proportional hazards, and because of inferential problems associated with the incorporation of time-varying covariates when death is a competing event, such covariate function was utilized in a heuristic sense to demonstrate nonproportional hazards [22].

All patients active at the end of follow-up were treated as censored.

All analysis was adjusted for covariates. Finally, collinearity among variables was tested and if statistically significant interactions were present, 1 of them was excluded. Covariates were included in the model when a $p$ value lower than 0.20 in the univariate analysis was found. Statistical significance was set at $p<0.05$. All statistical descriptive analyses were performed with SPSS 20.0 (SPSS, Chicago, USA). The competing risk analysis was performed using STATA 12 (StataCorp LP, College Station, TX, USA) and the package cmprsk: Subdistribution Analysis for Competing Risks, R version3.0.2 (R Foundation for Statistical Computing).

\section{Results}

During the study period (10 years), a total of 1231 patients were treated by dialysis: 301 by high volume $\mathrm{PD}(24.4 \%)$ and 930 by $\mathrm{HD}$ (75.6\%), of which 323 were treated by conventional, 519 were treated by prolonged, and 88 continuous HD.

In Table 1, we present the main characteristics of the general study population. The mean age was $66.8 \pm 15.7$ years, $210(69.8 \%)$ patients were male, $245(81.4 \%)$ of patients were Caucasian, and the mean patient weight was $71.6 \pm 10.7 \mathrm{~kg}$ (148 (49.2\%) were obtained by a digital scale, 101 (34.9\%) were obtained by bed scale and $52(17.3 \%)$ were calculated from two variable formulas).

Most of the patients (66.8\%) were in the intensive care unit and needed vasoactive drugs and mechanical ventilation (62.8\% and $70.3 \%$, respectively); 205 patients $(68.1 \%)$ had low urine output (less than $400 \mathrm{ml} /$ day), and the mean ATN-index specific score (ISS) was $0.63 \pm 0.18$. Sepsis was the main cause of AKI (53.2\%) followed by heart failure (26.9\%). Uremia or azotemia was the main indication for dialysis (63.1\%). The median number of high volume sessions was 7 , with a range of 5-11 and the delivered urea Kt/V was $0.56 \pm 0.18$ /session and $3.9 \pm 0.8 /$ wk.

Table 1 also shows the characteristics of the study population divided into two different time periods of PD treatment. Over the years, the prevalence of septic AKI patients treated 
Table 1. Clinical data of acute kidney injury patient treated with high volume peritoneal dialysis according to time period of high volume peritoneal dialysis treatment.

\begin{tabular}{|c|c|c|c|c|}
\hline & $\begin{array}{l}\text { General } \\
(n=301)\end{array}$ & $\begin{array}{l}2004-2008 \\
(n=168)\end{array}$ & $\begin{array}{l}2009-2014 \\
(n=133)\end{array}$ & $\mathbf{P}$ \\
\hline Age (years) & $66.8 \pm 15.7$ & $64.7 \pm 15.1$ & $69.8 \pm 15.9$ & 0.04 \\
\hline Male sex (\%) & $210(69.8)$ & $120(71.4)$ & $91(68.4)$ & 0.33 \\
\hline Caucasian patients (\%) & $245(81.4 \%)$ & $33(79.2)$ & $111(83.4)$ & 0.51 \\
\hline Weight (kg) & $71.6 \pm 10.7$ & $70.1 \pm 10.1$ & $72.5 \pm 10.9$ & 0.43 \\
\hline ICU (\%) & $201(66.8)$ & $119(70.8)$ & $80(60.2)$ & 0.05 \\
\hline \multicolumn{5}{|l|}{ Dialysis indication } \\
\hline Azotemia (\%) & $190(63.1)$ & $110(65.5)$ & $83(62.4)$ & 0.81 \\
\hline Hyperkalemia (\%) & 39 (12.6) & $22(13.1)$ & $14(10.5)$ & 0.53 \\
\hline Fluid overload (\%) & $61(20.3)$ & $34(20.2)$ & $27(20.3)$ & 0.59 \\
\hline Others * $(\%)$ & 11(3.6) & $6(3.5)$ & $5(3.8)$ & 0.85 \\
\hline \multicolumn{5}{|l|}{ Main diagnosis } \\
\hline Sepsis (\%) & $166(55.1)$ & $105(62.5)$ & $62(46.6)$ & 0.04 \\
\hline Cardiovascular (\%) & $78(25.9)$ & $39(23.2)$ & $41(30.8)$ & 0.11 \\
\hline Others** $(\%)$ & $57(18.9)$ & $24(14.3)$ & $30(22.6)$ & 0.77 \\
\hline \multicolumn{5}{|l|}{ AKI etiology } \\
\hline Sepsis (\%) & $160(53.2)$ & $104(61.9)$ & $63(47.4)$ & 0.04 \\
\hline i ATN (\%) & $81(26.9)$ & $40(23.9)$ & $42(31.6)$ & 0.09 \\
\hline Others *** $(\%)$ & $60(19.9)$ & $24(14.3)$ & $25(18.8)$ & 0.31 \\
\hline ICU admission (\%) & $201(66.8 \%)$ & $124(73.8)$ & $84(63.1)$ & 0.08 \\
\hline Mechanical ventilation (\%) & $213(70.3)$ & $121(72)$ & $85(63.9)$ & 0.23 \\
\hline Vasoactive drugs (\%) & $189(62.8)$ & $108(64.3)$ & $81(60.9)$ & 0.31 \\
\hline Urine output (<400 ml/day) & $205(68.1)$ & $111(66.1)$ & $91(68.4)$ & 0.44 \\
\hline ATN-ISS & $0.63 \pm 0.18$ & $0.66 \pm 0.19$ & $0.62 \pm 0.16$ & 0.08 \\
\hline Number of sessions (days) & $7(5-11)$ & $6(5-10)$ & $7(6-12)$ & 0.19 \\
\hline Follow-up (days) & $9(6-14)$ & $8(5-13)$ & $10(6-14)$ & 0.11 \\
\hline Mortality after 30 days (\%) & $180(59.8)$ & $111(66.1)$ & 69 (51.9) & 0.049 \\
\hline
\end{tabular}

ICU: intensive care unit, i ATN: ischemic acute tubular necrosis, ATN-ISS: acute tubular necrosis individual severity score

* others: acidosis, more than one indication;

** others: liver diseases and post surgery;

*** others: nephrotoxic AKI, obstructive AKI and mixed AKI

doi:10.1371/journal.pone.0126436.t001 
Table 2. Prescription and metabolic and fluid control of acute kidney injury patient treated with high volume peritoneal dialysis according to time period.

\begin{tabular}{|c|c|c|c|c|}
\hline & Overall $(n=301)$ & $2004-2008(n=168)$ & $2009-2014(n=133)$ & $\mathbf{P}$ \\
\hline Pre BUN (mg/dl) & $113.7 \pm 28.3$ & $118.7 \pm 29.3$ & $111.7 \pm 21.9$ & 0.56 \\
\hline Pre creatinine & $5.7 \pm 2.8$ & $5.9 \pm 2.9$ & $5.4 \pm 2.3$ & 0.78 \\
\hline \multicolumn{5}{|l|}{ BUN after (mg/dl) } \\
\hline 1st session & $95 \pm 42$ & $95 \pm 42$ & $89 \pm 32$ & 0.34 \\
\hline 2nd session & $86 \pm 31$ & $86 \pm 31$ & $79 \pm 21$ & 0.29 \\
\hline 3rd session & $71 \pm 27$ & $73 \pm 28$ & $69 \pm 19$ & 0.39 \\
\hline 4th session & $62 \pm 18$ & $64 \pm 18$ & $56 \pm 22$ & 0.41 \\
\hline 5th session & $54 \pm 15$ & $55 \pm 15$ & $51 \pm 11$ & 0.53 \\
\hline \multicolumn{5}{|c|}{ Creatinine after (mg/dl) } \\
\hline 1st session & $5.3 \pm 1.5$ & $5.1 \pm 1.5$ & $5.4 \pm 1.6$ & 0.64 \\
\hline 2nd session & $4.7 \pm 1.2$ & $4.6 \pm 1.2$ & $4.9 \pm 1.4$ & 0.61 \\
\hline 3rd session & $4.5 \pm 1.3$ & $4.3 \pm 1.3$ & $4.7 \pm 1.5$ & 0.76 \\
\hline 4th session & $4.0 \pm 1.1$ & $3.9 \pm 1.1$ & $4.2 \pm 1.3$ & 0.47 \\
\hline 5th session & $3.8 \pm 1.1$ & $3.7 \pm 1.1$ & $4.1 \pm 1.2$ & 0.71 \\
\hline \multicolumn{5}{|c|}{ Bicarbonate (mEq/l) } \\
\hline 1st session & $17.4 \pm 4.7$ & $16.4 \pm 4.7$ & $18.1 \pm 4.9$ & 0.54 \\
\hline 2nd session & $20.8 \pm 4.5$ & $20.1 \pm 4.3$ & $21.1 \pm 4.7$ & 0.59 \\
\hline 3rd session & $21.6 \pm 3.5$ & $21.2 \pm 3.5$ & $21.9 \pm 4.5$ & 0.69 \\
\hline 4th session & $22.6 \pm 3.5$ & $22.5 \pm 3.4$ & $22.8 \pm 4.4$ & 0.71 \\
\hline 5th session & $22.2 \pm 3.6$ & $22.8 \pm 3.2$ & $23.7 \pm 4.1$ & 0.77 \\
\hline \multicolumn{5}{|l|}{ UF (ml/session) } \\
\hline 1st session & $275(-370-515)$ & $230(-330-465)$ & $344(-87-565)$ & 0.14 \\
\hline 2nd session & $989.8(693.4-1221.8)$ & $919.8(683.4-1119.8)$ & 1015 (756-1348) & 0.09 \\
\hline 3rd session & 1183 (901.4-1523) & $1023(800.4-1323)$ & 1405 (1018-1768) & 0.04 \\
\hline 4th session & $1512.9(1070-1602)$ & $1102.9(870-1402)$ & 1976 (1422-2099) & 0.01 \\
\hline 5th session & $1700.6(1158-1970)$ & $1200.6(958-1570)$ & $2012(1865-2314)$ & 0.018 \\
\hline \multicolumn{5}{|l|}{ FB after (g/day) } \\
\hline 1st session & $0.2 \pm 0.04$ & $0.5 \pm 0.1$ & $-0.1 \pm 0.02$ & 0.37 \\
\hline 2nd session & $-1.4 \pm 0.1$ & $-0.8 \pm 0.3$ & $-1.7 \pm 0.5$ & 0.19 \\
\hline 3rd session & $-1.9 \pm 0.4$ & $-1.1 \pm 0.4$ & $-2.2 \pm 0.6$ & 0.03 \\
\hline 4th session & $-2.1 \pm 1.9$ & $-1.4 \pm 0.5$ & $-2.9 \pm 0.9$ & 0.008 \\
\hline 5th session & $-2.2 \pm 1.1$ & $-1.2 \pm 0.4$ & $-2.3 \pm 0.6$ & 0.001 \\
\hline \multicolumn{5}{|l|}{ Prescribed Kt/V } \\
\hline Per session & $0.62 \pm 0.01$ & $0.67 \pm 0.11$ & $0.57 \pm 0.06$ & 0.03 \\
\hline Weekly & $4.34 \pm 0.01$ & $4.7 \pm 0.71$ & $3.9 \pm 0.51$ & 0.04 \\
\hline \multicolumn{5}{|l|}{ Delivered Kt/ V } \\
\hline Per session & $0.56 \pm 0.15$ & $0.58 \pm 0.18$ & $0.49 \pm 0.14$ & 0.04 \\
\hline Weekly & $3.9 \pm 0.8$ & $4.0 \pm 0.9$ & $3.4 \pm 0.7$ & 0.02 \\
\hline
\end{tabular}

doi:10.1371/journal.pone.0126436.t002

\section{Technique survival}

Peritonitis occurred in 31 patients (10.3\%) after 5.8 \pm 1.6 high volume PD sessions. Twenty-one patients $(67.8 \%)$ had the catheter removed, and the dialysis method was changed because of no improvement in laboratory or clinical parameters after 5 days of correct antibiotic treatment. The main agents were Pseudomonas aeruginosa, (14 cases, 45.1\%), fungi ( 7 cases, 22.6\%), Staphylococcus aureus ( 5 cases, 16.1\%) and acinetobacter ( 3 cases, 9.7\%). Antibiotic treatment 
Table 3. Mechanical and infectious complications related to high volume peritonealdialysis according to time period.

\begin{tabular}{|c|c|c|c|c|}
\hline PD complications & Overall( $(n=301)$ & $2004-2008(n=168)$ & $2009-2014(n=133)$ & $\mathbf{p}$ \\
\hline Peritonitis (\%) & $31(10.3)$ & $21(12.5)$ & $10(7.5)$ & 0.09 \\
\hline Mechanical (leakage and catheter tip migration (\%) & $44(14.6)$ & $31(18.5)$ & $13(9.8)$ & 0.04 \\
\hline
\end{tabular}

doi:10.1371/journal.pone.0126436.t003

was maintained from 14 to 21 days. Forty four patients presented mechanical complications (14.6\%) and leakage and tip catheter migration were the majority of the complications (79.5\%), with therapy being interrupted in 24 patients (54.5\%). In other cases, the catheter was reinserted, and the dialysate volume per cycle was reduced (1200-1500 $\mathrm{ml} /$ cycle).

Out of 301 patients, 51 were transferred to HD (16.9\%) during the study period. The main cause of technique failure was catheter dysfunction (47\%) followed by peritonitis (41.2\%), low ultrafiltration rate $(5.9 \%)$ and no metabolic control (3.9\%). The technique survival after 30 days was $84 \%$. Death was responsible for more than $50 \%$ of the study dropout with mechanical complications coming next. Table 3 summarizes the infectious and mechanical complications related to PD and Table 4 shows the causes of dropout. Mechanical complications were the most important cause of technique failure followed by peritonitis as shown in Fig 1.

There was change in TF during the study period: compared to 2004-2008, patients treated at 2009/2014 had a relative risk reduction of 0.86 (95\% confidence interval [CI] 0.77-0.96) (Fig 2). Five covariates presented a $p$ value lower than 0.20 in the univariate analysis and were included in the multivariate model: age $\geq 65$ years, sepsis, ATN-ISS $>0.65$, ICU admission and period of treatment. Three independent risk factors were identified: sepsis, period of treatment from 2004 to 2008 and age $>65$ years (Table 5).

\section{Patient survival}

Concerning patient outcome, (63) $20.9 \%$ of patients recovered renal function, whereas (7) $2.3 \%$ were kept on dialysis after 30 days of therapy. Change of the dialysis method occurred in $16.9 \%$ of patients because of refractory peritonitis or mechanical complications (leakage or UF failure).

There were 180 deaths (59.8\%) during the study. In fact, death was the leading cause of dropout (77.9\% of all cases) mainly by sepsis (58.3\%), followed cardiovascular disease (36.1\%).

Overall no adjusted patient survival at $41 \%$ after 30 days. Mortality rates improved over the years: compared to 2004 to 2008 patients, those treated at 2009 to 2014 had a relative risk reduction (HR) of 0.87 (95\% CI 0.79-0.98) (Fig 3). After the inclusion of all variables with a $p$ value lower than 0.20 at the univariate analysis (age $\geq 70$ years, sepsis, ATN-ISS $>0,65$, low urine output, ICU admission, UF $<500 \mathrm{ml} /$ day, positive fluid balance and the year the patient treated by PD) we ended up with 6 independent predictors of mortality: age $\geq 70$ (HR: 2.44, 95\% CI 2.15-2.77), ICU admission (HR 2.12, 95\% CI 1.67-3.64), ATN-ISS > 0.65 (HR: 1.18, 95\% CI, 1.03-1.35), sepsis (HR: 1.26, 95\% CI, 1.10-1.45), positive fluid balance (HR:1.58,95\%

Table 4. Dropout causes according to time period.

\begin{tabular}{|c|c|c|c|c|}
\hline Dropout causes & $\begin{array}{l}\text { overall } \\
(n=51)\end{array}$ & $\begin{array}{l}\text { Death censured } \\
2004-2008 \\
(n=37)\end{array}$ & $\begin{array}{l}2009-2014 \\
(n=14)\end{array}$ & $\mathbf{p}$ \\
\hline catheter dysfunction (\%) & $25(49)$ & $19(51.4)$ & $6(42.8)$ & 0.049 \\
\hline Peritonitis (\%) & $21(41.2)$ & $17(46)$ & $4(28.6)$ & 0.037 \\
\hline No metabolic or fluid control (\%) & $5(9.8)$ & $1(2.7)$ & $4(28.6)$ & 0.02 \\
\hline
\end{tabular}

doi:10.1371/journal.pone.0126436.t004 
$301 \mathrm{AKI}$ patients treated with high volume PD

death : 180 patients $(59.8 \%)$

survival: 121 patients $(40.2 \%)$

patients $(59.8 \%)$

$\downarrow$

recovery renal function: 63 patients $(20.9 \%)$

dialysis dependence: 7 patients $(2.3 \%)$

technique failure: 51 patients $(16.9 \%)$

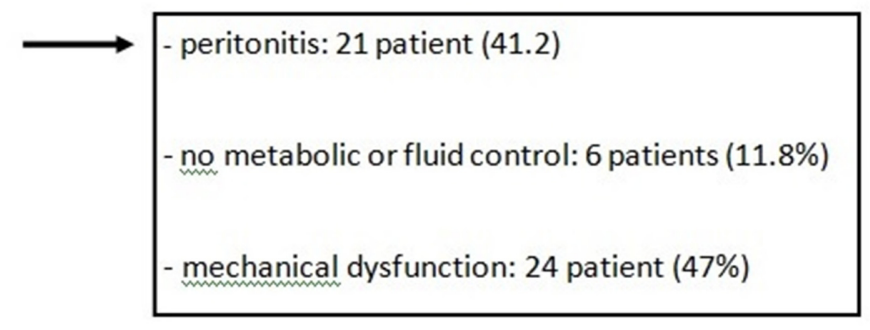

Fig 1. Acute kidney injury (AKI) patient outcome treated with high volume peritoneal dialysis.

CI, 1.46-2.73) and the year the patient treated with PD (2004 to 2008 compared to 2009 to 2014: HR: 0.87, 95\%CI, 0.79-0.98). A full description of patient survival according different subsets of patients can be seen in Table 6 .

\section{Discussion}

Observational studies provide valuable information in patient selection, clinical practice, and their relationship to patient and technique outcome. The present study is the largest cohort about PD in AKI that showed the improvement in AKI patient survival treated with PD and in its TF.

The demographic characteristics of our PD patients changed over time, we noted a reduction in septic patients, an increase in age and a decrease in patients admitted to ICU.

These changes in our patient profile likely reflect a change in clinical practice probably based on emerging data pointing to worse outcomes of septic and severe hypercatabolic patients treated with PD [23,24]. According to Chitalia [23], Phu [25] and Ponce et al [24], hemodialysis should be the first option of treatment for severe hypercatabolic septic patients because PD clearance is limited by dialysate flow, membrane permeability, and area and cannot be enough to keep adequate metabolic and fluid control of these patients. 


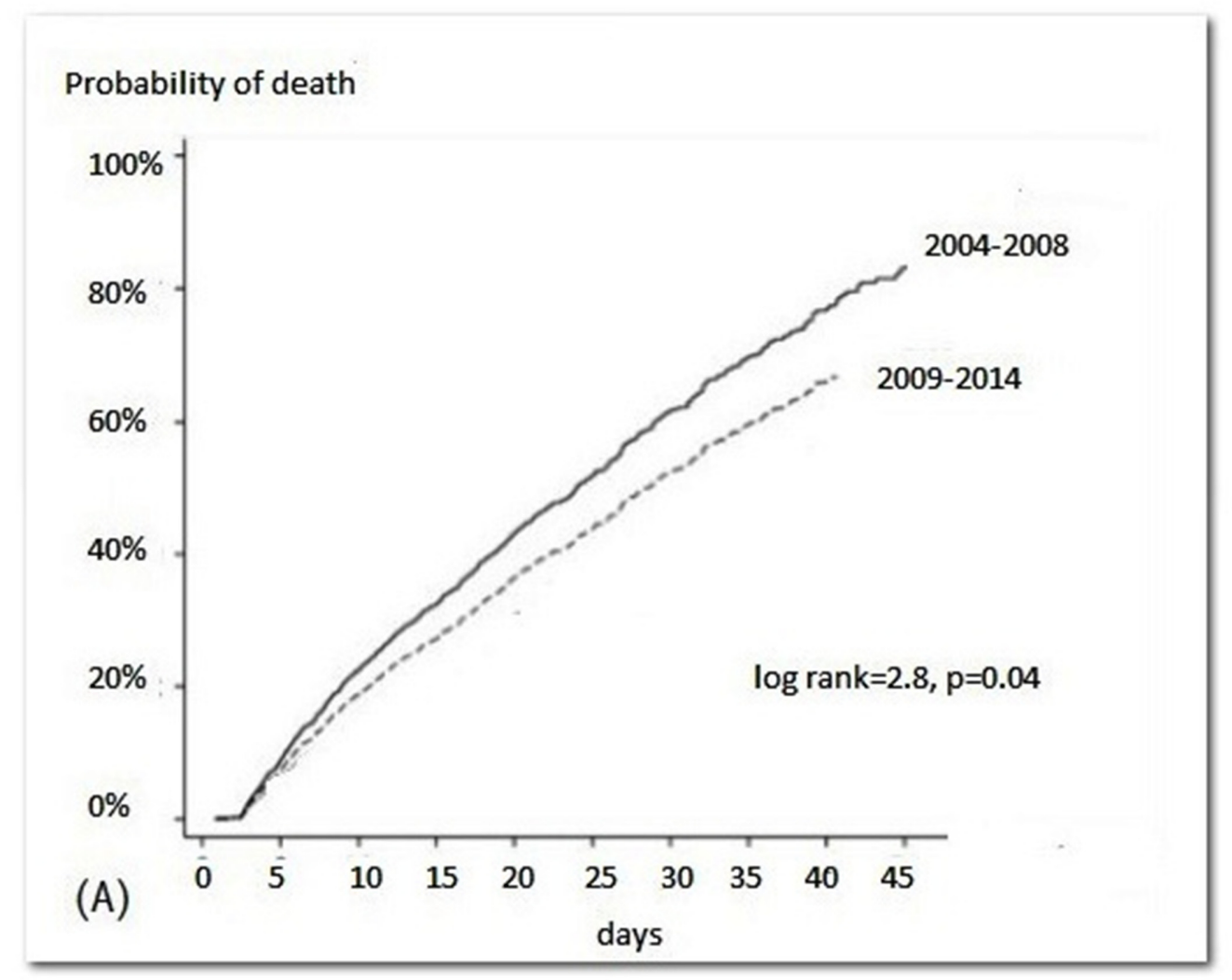

Fig 2. Probability of death according to time period.

doi:10.1371/journal.pone.0126436.g002

However, comparing our population with other but small studies cohorts, we still have a higher percentage of elderly, septic and critically AKI patients treated with PD when compared to the African and Indian cohorts. The mean age and the number of septic patients of our cohort were in average 15 years older and $30 \%$ more frequent than most others PD cohorts, respectively [23,26,27].

In terms of $\mathrm{PD}$ doses, there was a decrease in prescribed and delivered $\mathrm{Kt} / \mathrm{V}$, without changes in metabolic control. There was significant reduction in BUN and creatinine levels, with stabilization of BUN values (around $55 \mathrm{mg} / \mathrm{dl}$ ) and bicarbonate (around $23 \mathrm{mEq} / \mathrm{l}$ ) after four sessions in both periods of study. The most appropriate dose for PD in the management of patients with AKI is poorly defined. This reduction in prescribed doses reflects the results of previous studies $[28,29]$. Ponce et al have compared very high volume (prescribed Kt/V = 0.8)

Table 5. Subdistribuition Hazard Ratio of Covariates for technique failure.

\begin{tabular}{lll}
\hline Variables & HR (Cl95\%) & p \\
\hline 2004-2008 & ref & \\
2009-2014 & $0.92(0.87-0.97)$ & 0.01 \\
Age $>$ 65 years & $1.26(1.04-1.39)$ & 0.049 \\
ATN-ISS > 0.65 & $1.11(0.98-2.11)$ & 0.29 \\
Sepsis & $1.32(1.18-2.64)$ & 0.02 \\
ICU admission & $1.12(0.98-1.63)$ & 0.12 \\
\hline
\end{tabular}

doi:10.1371/journal.pone.0126436.t005 


\section{Probability of \\ technique failure}

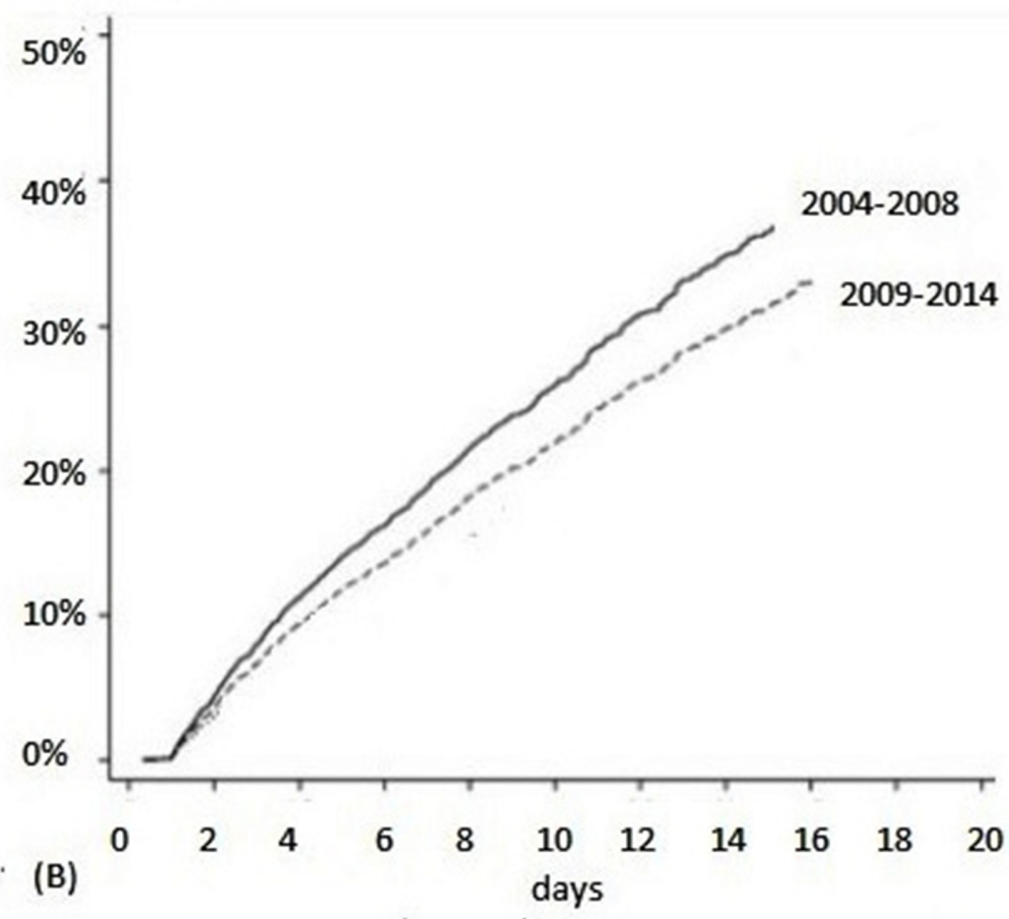

Fig 3. Probability of technique failure according to time period.

doi:10.1371/journal.pone.0126436.g003

with lower volume acute $\mathrm{PD}$ (prescribed $\mathrm{Kt} / \mathrm{V}=0.5$ ) and have shown no benefit from aiming for the higher target; the lower-dose group achieved a Kt/V urea of 3.43 and did as well as the higher-dose group, which achieved a Kt/V of 4.13 [29]. However, some studies have shown very good outcomes with much lower doses than those used in Ponce-Gabriel's study [23,27] and the ideal delivered PD doses can be lower than that reported by Ponce et al [28,29]. There was an increase in cumulative negative fluid balance and UF over the years after 3 PD sessions. These results reflect results of previous studies reporting that low urine output and fluid overload were associated with worse prognosis of AKI patients [6,30,31].

Table 6. Subdistribuition Hazard Ratio of Covariates for mortality.

\begin{tabular}{lll}
\hline Variables & HR (Cl95\%) & p \\
\hline 2004-2008 & ref & \\
\hline 2009-2014 & $0.94(0.89-0.98)$ & 0.01 \\
\hline Age $>$ 70 years & $2.44(2.15-2.77)$ & 0.009 \\
ATN-ISS > 0.65 & $1.18(1.03-1.35)$ & 0.04 \\
Sepsis & $1.26(1.10-1.45)$ & 0.02 \\
ICU admission & $2.12(1.67-3.64)$ & 0.003 \\
Low urine output & $1.17(0.94-1.49)$ & 0.09 \\
UF < 500 ml/day & $1.19(0.91-1.54)$ & 0.25 \\
positive fluid balance & $1.58(1.46-2.73)$ & 0.008 \\
\hline
\end{tabular}

doi:10.1371/journal.pone.0126436.t006 


\section{Technique survival: main findings}

Traditionally, peritonitis is the leading cause of TF in chronic PD patients, which was different in the present study. In fact, mechanical complications (tip catheter migration) were the first cause of TF, followed by peritonitis. In the most cases of leakage, dialysate volume per cycle was reduced from $2000 \mathrm{ml}$ to 1200 or $1500 \mathrm{ml} / \mathrm{cycle}$ and PD could be continued.

Concerning infectious complications, peritonitis levels were similar to those reported in the literature (12\%-15\%) and fungi and Pseudomonas aeruginosa were the most common agents $[3,6,8,17]$. Previous studies reported lower prevalence of mechanical complications; however they excluded patients who had them in the first 24 hours of PD treatment $[3,6]$.

There was change in TF during the study period: compared to 2004-2008, patients treated at 2009/2014 had a relative risk reduction of 0.86 (95\% confidence interval [CI] 0.77-0.96) and three independent risk factors were identified: period of treatment at 2009 and 2014, sepsis and age $>65$ years. We also can observe that there was change in causes of TF over the years: a decrease in peritonitis and catheter dysfunction and an increase in no metabolic and fluid control. There is no data in the literature to be comparable to our study. We believe that the impact of period of study occurred because the team achieved more experience in catheter insertion and cycler preparation. Exploring how the sepsis can be risk factor to TF, it is known that these patients are, frequently, severe hypercatabolic that may impair metabolic and fluid control by PD, leading to dropout study $[3,23,31]$.

\section{Mortality}

Despite all efforts, mortality rates remain extremely high in dialysis AKI patients [32-37]. Not surprisingly, death was responsible for more than $50 \%$ of the study dropout and a survival patients after 30 days was $40 \%$. In line with previous reports, the mortality of AKI patients undergoing different methods of dialysis ranged from $40-80 \%$, according to AKI etiology and severity of patients $[33,37]$.

In this study, mortality rates improved over the years: compared to 2004 to 2008 patients, those treated at 2009 to 2014 had a relative risk reduction (HR) of 0.87 (95\% CI 0.79-0.98) and more five independent predictors of mortality were identified: age $\geq 70$ years, ICU admission, ATN-ISS $>0.65$, sepsis and positive fluid balance. These results agree with previous studies reporting that higher age, fluid overload, and sepsis were associated with worse prognosis of AKI patients [32-34,38].

Recent studies have shown that fluid overload is a risk factor of death in critical patients $[30,31,38]$. In chronic dialysis patients treated with automated PD, the work by Brown et al. [31] showed that UF lower than $750 \mathrm{ml} / \mathrm{d}$ was associated with death. Ponce et al [6], in study that evaluated 150 AKI patients treated with high volume PD, showed that higher age, sepsis, lower urine output, ultrafiltration lower than $500 \mathrm{ml} /$ day after three sessions were identified as risk factors for death.

Finally, the improvement occurred in patients treated at 2009 to 2014 presenting better survival than those from 2004 to 2009. At first glance the better clinical profile of patients starting dialysis could be an explanation, but the difference persisted even after adjustment for several covariates. The factors responsible for this improvement were not clear, but are probably related to an improvement in clinical practice including better fluid control. Another possibility is related to a better management of PD-related infections that has been massively tackled by medical societies through development of campaigns and development and diffusion of clinical guidelines. Importantly, our results are in line with previous data in AKI patients from large cohorts that looked into secular trends: Waikar et al. in a large study with AKI patients in dialysis reported a significant improvement ranging from 3 to $5 \%$ in 2 to 5 years patient survival [37]. 
This study presents several limitations. First, this is an observational study and, as such, all significant associations found should be interpreted with caution. Second, residual renal function was not available for the majority of patients and was not included in our analysis. Nevertheless, our study has some very important strengths: it was a prospective, cohort with outcomes adjusted for several clinical covariates using a competing risks analysis. Its characteristics share several similarities with other cohorts from different parts of the world supporting the quality of our data.

In conclusion, we described the largest cohort of PD in AKI patients in the world. This is the first study reporting a significant trend in TF and patient survival improvement throughout the vintages in a developing country and after adjusting for multiple covariates.

\section{Author Contributions}

Conceived and designed the experiments: DP AB. Performed the experiments: AB DP CG MB. Analyzed the data: $\mathrm{DP}$ AB. Contributed reagents/materials/analysis tools: DP AB. Wrote the paper: DP AB.

\section{References}

1. Steiner RW. Continuous equilibration peritoneal dialysis in acute renal failure. Perit Dial Int J Int Soc Perit Dial. 1989; 9(1):5-7.

2. Nolph KD, Sorkin MI. Peritoneal dialysis in acute renal failure. In: Brenner BM, Lazarus MJ, organizadores. Acute Renal Failure. 2o ed New York: Churchill Livingstone; 1988. p. 809-34.

3. Rao P, Passadakis P, Oreopoulos DG. Peritoneal dialysis in acute renal failure. Perit Dial Int. 1 de janeiro de 2003; 23(4):320-2. PMID: 12968838

4. Gabriel DP, Nascimento GVR, Caramori JT, Martim LC, Barretti P, Balbi AL. Peritoneal dialysis in acute renal failure. Ren Fail. 2006; 28(6):451-6. PMID: 16928612

5. Gabriel DP, Nascimento GVR do, Caramori JT, Martim LC, Barretti P, Balbi AL. High volume peritoneal dialysis for acute renal failure. Perit Dial Int J Int Soc Perit Dial. junho de 2007; 27(3):277-82.

6. Ponce D, Berbel MN, Regina de Goes C, Almeida CTP, Balbi AL. High-volume peritoneal dialysis in acute kidney injury: indications and limitations. Clin J Am Soc Nephrol CJASN. junho de 2012; 7 (6):887-94. doi: 10.2215/CJN.11131111 PMID: 22461532

7. Ronco C. Can peritoneal dialysis be considered an option for the treatment of acute kidney injury? Perit Dial Int J Int Soc Perit Dial. junho de 2007; 27(3):251-3.

8. Passadakis PS, Oreopoulos DG. Peritoneal dialysis in patients with acute renal failure. Adv Perit Dial Conf Perit Dial. 2007; 23:7-16.

9. Ronco C. Factors affecting hemodialysis and peritoneal dialysis efficiency. Contrib Nephrol. 2006; 150:1-12. PMID: 16720985

10. Chionh CY, Ronco C, Finkelstein FO, Soni SS, Cruz DN. Acute peritoneal dialysis: what is the "adequate" dose for acute kidney injury? Nephrol Dial Transplant Off Publ Eur Dial Transpl Assoc-Eur Ren Assoc. outubro de 2010; 25(10):3155-60.

11. Katirtzoglou A, Kontesis P, Myopoulou-Symvoulidis D, Digenis GE, Symvoulidis A, Komninos Z. Continuous Equilibration Peritoneal Dialysis (cepd) in Hypercatabolic Renal Failure. Perit Dial Int. 10 de janeiro de 1983; 3(4):178-80.

12. Mehta RL, Kellum JA, Shah SV, Molitoris BA, Ronco C, Warnock DG, et al. Acute Kidney Injury Network: report of an initiative to improve outcomes in acute kidney injury. Crit Care Lond Engl. 2007; 11 (2):R31. PMID: 17331245

13. Honore PM, Jacobs R, Joannes-Boyau O, De Regt J, Boer W, De Waele E, et al. Septic AKI in ICU patients. diagnosis, pathophysiology, and treatment type, dosing, and timing: a comprehensive review of recent and future developments. Ann Intensive Care. 2011; 1(1):32. doi: 10.1186/2110-5820-1-32 PMID: 21906387

14. Schrier RW. Acute renal failure. Kidney Int. 1979; 15(205). PMID: 513485

15. Korbet SM. Acute peritoneal dialysis prescription. In: Peter G. Blake, Todd S. Ing, Daugirdas JT, organizadores. Handbook of Dialysis. 3o ed Philadelphia: Lippincott Williams \& Wilkins; 2001. p. 333-42.

16. Watson PE, Watson ID, Batt RD. Total body water volumes for adult males and females estimated from simple anthropometric measurements. Am J Clin Nutr. janeiro de 1980; 33(1):27-39. PMID: 6986753 
17. Ponce D, Balbi AL, Amerling R. Advances in peritoneal dialysis in acute kidney injury. Blood Purif. 2012; 34(2):107-16. doi: 10.1159/000341648 PMID: 23095409

18. Druml W. Nutritional support in acute renal failure. In: Mitch WE, Klahr S, organizadores. Handbook of nutrition and the kidney. 3o ed Philadelphia: Lippincott-Raven; 1998. p. 213-36.

19. DuBois D, DuBois EF. THE MEASUREMENT OF THE SURFACE AREA OF MAN. Arch Intern Med. maio de 1915; XV(5_2):868-81.

20. Chumlea WC, Roche AF, Steinbaugh ML. Estimating stature from knee height for persons 60 to 90 years of age. J Am Geriatr Soc. fevereiro de 1985; 33(2):116-20. PMID: 3968366

21. Liaño F, Gallego A, Pascual J, García-Martín F, Teruel JL, Marcén R, et al. Prognosis of acute tubular necrosis: an extended prospectively contrasted study. Nephron. 1993; 63(1):21-31. PMID: 8446248

22. Fine JP, Gray RJ. A Proportional Hazards Model for the Subdistribution of a Competing Risk. J Am Stat Assoc. 1 de junho de 1999; 94(446):496-509.

23. Chitalia VC, Almeida AF, Rai H, Bapat M, Chitalia KV, Acharya VN, et al. Is peritoneal dialysis adequate for hypercatabolic acute renal failure in developing countries? Kidney Int. fevereiro de 2002; 61(2):74757. PMID: 11849419

24. Ponce $D$, Balbi AL. Peritoneal dialysis in acute kidney injury: a viable alternative. Perit Dial Int J Int Soc Perit Dial. 2011; 31(4):387-9.

25. Phu NH, Hien TT, Mai NTH, Chau TTH, Chuong LV, Loc PP, et al. Hemofiltration and peritoneal dialysis in infection-associated acute renal failure in Vietnam. N Engl J Med. 19 de setembro de 2002; 347 (12):895-902. PMID: 12239258

26. George J, Varma S, Kumar S, Thomas J, Gopi S, Pisharody R. Comparing continuous venovenous hemodiafiltration and peritoneal dialysis in critically ill patients with acute kidney injury: a pilot study. Perit Dial Int J Int Soc Perit Dial. agosto de 2011; 31(4):422-9. doi: 10.3747/pdi.2009.00231 PMID: 21357934

27. Kilonzo KG, Ghosh S, Temu SA, Maro V, Callegari J, Carter M, et al. Outcome of acute peritoneal dialysis in northern Tanzania. Perit Dial Int J Int Soc Perit Dial. junho de 2012; 32(3):261-6.

28. Ponce Gabriel D, Caramori JT, Martim LC, Barretti P, Balbi AL. High volume peritoneal dialysis vs daily hemodialysis: a randomized, controlled trial in patients with acute kidney injury. Kidney Int Suppl. abril de 2008;(108: ):S87-93. doi: 10.1038/sj.ki.5002608 PMID: 18379555

29. Ponce D, Brito GA, Abrão JG, Balb AL. Different prescribed doses of high-volume peritoneal dialysis and outcome of patients with acute kidney injury. Adv Perit Dial Conf Perit Dial. 2011; 27:118-24. PMID: 22073842

30. Silversides JA, Pinto R, Kuint R, Wald R, Hladunewich MA, Lapinsky SE, et al. Fluid balance, intradialytic hypotension, and outcomes in critically ill patients undergoing renal replacement therapy: a cohort study. Crit Care Lond Engl. 18 de novembro de 2014; 18(6):624. PMID: 25407408

31. Brown EA, Davies SJ, Rutherford P, Meeus F, Borras M, Riegel W, et al. Survival of functionally anuric patients on automated peritoneal dialysis: the European APD Outcome Study. J Am Soc Nephrol JASN. novembro de 2003; 14(11):2948-57. PMID: 14569106

32. Levy MM, Macias WL, Vincent J- L, Russell JA, Silva E, Trzaskoma B, et al. Early changes in organ function predict eventual survival in severe sepsis. Crit Care Med. outubro de 2005; 33(10):2194-201. PMID: 16215369

33. Uchino S, Kellum JA, Bellomo R, Doig GS, Morimatsu H, Morgera S, et al. Acute renal failure in critically ill patients: a multinational, multicenter study. JAMA J Am Med Assoc. 17 de agosto de 2005; 294 (7):813-8.

34. Ricci Z, Ronco C, D'Amico G, De Felice R, Rossi S, Bolgan I, et al. Practice patterns in the management of acute renal failure in the critically ill patient: an international survey. Nephrol Dial Transplant Off Publ Eur Dial Transpl Assoc_Eur Ren Assoc. março de 2006; 21(3):690-6.

35. Chionh CY, Soni SS, Finkelstein FO, Ronco C, Cruz DN. Use of peritoneal dialysis in AKI: a systematic review. Clin J Am Soc Nephrol CJASN. outubro de 2013; 8(10):1649-60. doi: 10.2215/CJN.01540213 PMID: 23833316

36. Cullis B, Abdelraheem M, Abrahams G, Balbi A, Cruz DN, Frishberg Y, et al. Peritoneal dialysis for acute kidney injury. Perit Dial Int J Int Soc Perit Dial. agosto de 2014; 34(5):494-517.

37. Waikar SS, Curhan GC, Wald R, McCarthy EP, Chertow GM. Declining mortality in patients with acute renal failure, 1988 to 2002. J Am Soc Nephrol JASN. abril de 2006; 17(4):1143-50. PMID: 16495376

38. Libório AB, Leite TT, Neves FM de O, Teles F, Bezerra CT de M. AKI complications in critically ill patients: association with mortality rates and RRT. Clin J Am Soc Nephrol CJASN. 7 de janeiro de 2015; 10(1):21-8. doi: 10.2215/CJN.04750514 PMID: 25376761 